\title{
A Longitudinal Effect of Intergenerational Support on Psychological Well-Being of Rural Elderly
}

\author{
Wang Ping, Zhang Wenjian*, Lian Yawei, Liu Jiao \\ School of Management, Xi'an University of Science and Technology, Xi'an, China
}

Email address:

zwjian90@126.com (Zhang Wenjian)

${ }^{*}$ Corresponding author

To cite this article:

Wang Ping, Zhang Wenjian, Lian Yawei, Liu Jiao. A Longitudinal Effect of Intergenerational Support on Psychological Well-Being of Rural Elderly. Humanities and Social Sciences. Vol. 5, No. 3, 2017, pp. 121-129. doi: 10.11648/j.hss.20170503.12

Received: April 10, 2017; Accepted: April 21, 2017; Published: June 3, 2017

\begin{abstract}
Using the data from a 5-wave longitudinal survey "Well-being of Elderly in Anhui Province, China" conducted in 2001, 2003, 2006, 2009 and 2012 by the Institute for Population and Development Studies of Xi'an Jiaotong University. This study employs Hierarchical Linear Models to analyze longitudinal effect of intergenerational support on the psychological well-being of the rural elderly. The results show that intergenerational financial support, assistance with household chores provided to adult children, receiving personal care, and emotional support between the elderly and children promoted psychological well-being of the elderly, however receiving assistance with household chores from adult children decreased psychological well-being of the elderly. This study suggests that family intergenerational support, which is mainly needs based, and conditional on culturally prescribed expectations, can enhance psychological well-being of the elderly in rural. This study reflects influential mechanism of intergenerational support on the psychological well-being of rural elderly. In the background of rural labor migration, what the author finds, for us to understand effects of intergenerational support from the different family structure on the rural elderly's health, make public policy analysis or construct social support system, has certain practical significance.
\end{abstract}

Keywords: Intergenerational Support, Psychological Well-Being, Longitudinal Data, Rural Elderly

\section{Introduction}

Social modernization and the transformation of China's economic structure, brought the flow of labor market, to promote the reduction of family size, thus affecting the rural family structure changes [1]. With the "silver wave" impact, China has quickly entered the aging society, in the family pension as the main pension way of China's rural areas, the elderly psychological well-being status of the development of the cause of aging, social development is facing a major Problem [2]. In rural areas of China, because the adult children provide intergenerational support constitute almost the entire contents of social support of the elderly, the traditional family structure to a non-traditional family structures (such as empty nesters, inter-generational families, family network) transformation [3], it brought the family room of isolation and family functions (such as pension support) the weakening of the social resources available to the elderly decreased, adult children and elderly parents separated increases may reduce the ability of family support for the elderly, and ultimately lead to decline psychological well-being of elderly [4].

So far, domestic scholars to study the factors that affect the personal psychological well-being of the rural elderly, mainly in the medical field [5], the studies from the perspective of social security cut into the rural elderly psychological health are few [6], the fewer studies with intergenerational support as major exploratory factors. The research on the intergenerational support of the rural family and the psychological well-being of the elderly is gradually concerned. The previous research is mainly based on the analysis of the cross-sectional data, while the systematic follow-up investigation and the causal statistical analysis are still lacking, and the study of family intergenerational support impact on 
the psychological well-being of the rural elderly is slightly vacant. Therefore, this study aims to explore a longitudinal effect of intergenerational support on psychological well-being of rural elderly and explore its impact mechanism.

\section{Hypothesis}

Psychological well-being refers to the individual can correctly understand themselves, timely adjustment of their own mentality, so that the psychological state in order to adapt to the outside world [7]. The psychological well-being of the elderly is affected by many factors, and its adverse psychological well-being development curve is influenced by its own internal factors and foreign support. Therefore, when examining the influence of intergenerational support on the development trend of psychological well-being of the elderly, Stripping out the development trend of the elderly psychological well-being. In the Chinese family support system, there is a two-way intergenerational support between the elderly and the children. Thus, this article will be from the three basic aspects of the two-way interdepartmental support financial support, daily care (assistance with household chores and personal care) and emotional support for research, and the definition of financial support, assistance with household chores and personal care for the elderly to receive from their children and provide to their children; emotional support refers to the degree of emotional development between the two sides, itself is a two-way exchange [8-10]. In the more traditional Chinese culture, social changes, the number of children and many other factors, including the impact of [11], the intergenerational support is particularly important for elderly, but not all support is beneficial to the elderly, so it is necessary to explore in depth.

With the development of social economy, the financial support in the Chinese family pension is no longer simple bottom-up flow, but the performance of two-way flow [12]. The elderly gets the financial support from children to make the life more secure, to make the value of life and the role of parents is recognized by friends, and to make self-esteem is maintained, so that they can actively or passively communicate life experience with peers and youngers, aimed to getting mutual help and communicating with people in a happy life. Therefore, that enhances the old people's happiness and reduces loneliness, and ultimately it can improve the psychological well-being level and reduce depression in older people [13]. A lack of financial support lead to the economic dependence on their children and makes the elderly has low self-esteem and negative emotions, worsening [14]. psychological well-being status of the elderly. The elderly who has a certain financial support also can provide financial support for their children, so most of them have a higher status in family, and economic independence in exchange for the better care and more spiritual comfort from their children, their psychological well-being will be better. Of course, the elderly parents provide financial support may also reflects their willingness to take the initiative contact with their children, and have a harmonious generation relationship, so as to improve the psychological well-being status and reduce levels of depression $[15,16]$.

Therefore, this paper puts forward the hypothesis that the influence of two-way financial support on mental health of the elderly is as follows:

Hypothesis a1: financial support for the elderly can reduce the level of depression

Because of the comprehensive effect of the backward rural family, society, economy and culture, daily life care of older persons in rural areas depends on the children, the assistance with household chores and personal care from children has a significant impact on quality of life in the elderly [17]. Daily life function is one of the important indexes to evaluate the health status of the elderly, self-care ability, and it has close relationship with physiological function and psychological well-being, it also decides the economic status, activity and social function of the elderly [18]. Aging may lead to the decline of the elderly immune function and physical strength, causing the obstacles to the daily life of the elderly [19], thus the elderly needs more care. The rural elderly people provide the assistance with household chores as much as possible for children in real life. The elderly can provide assistance with household chores reflects that their health condition is still good, it also makes the elderly have a better sense of interaction, which may reduce the elderly depression. Chinese studies made by Kwag $\mathrm{K} \mathrm{H}$ also found that giving children more care will worsen the health status of the elderly, and may endanger their psychological well-being [20]. Song Lu found that care for grandchildren can bring better psychological well-being for the elderly people in rural China [21]. In summary, in present, the research on the rural family intergenerational support for the development of psychological well-being of the elderly is still lack, let alone the deep study of the system by dividing the daily care into assistance with household chores and personal care.

Therefore, this paper puts forward the following assumptions about the effects of daily care (assistance with household chores and personal care) on psychological well-being of the elderly:

Hypothesis b1: the elderly receive (provide) assistance with household chores can reduce their level of depression

Hypothesis c1: the elderly receive (provide) personal care can reduce their level of depression

Social support is an important social factor that affects people's physical and psychological well-being, the definition of social support can be divided into two categories: visual support and perceived support [22, 23]. The relationship between perceived support and psychological well-being is most close. In the past study on the relationship between the social support and health status of the elderly, emotional support has been considered to be vital critical factor, it is also an important dimension which measure intergenerational emotional support level and potential financial and life care support, it can promote the psychological well-being of the elderly rather than daily care and financial support. Study on Chinese shows moderate emotional support has a positive impact on the psychological health of the elderly than 
financial support, and research shows that children are the important factor to influence the life satisfaction of the elderly, The effect does not depend on the number, it depends on whether children can provide their parents with more emotional and behavior surpport or not, so emotional support can improve the life satisfaction of the elderly [24]. And the social support especially has the most obvious influence on depression of elderly, so this paper believes that the rural elderly life circle is small, monotonous, and reality which elders depend on children supports that intergenerational emotional support can be good for the elderly to resolve loneliness, and also indicates that the elderly will keep them from future threats, therefore, emotional support can reduce the level of depression in the elderly.

Therefore, this paper proposes that the influence of emotional support on psychological well-being of the elderly is as follows:

Hypothesis d: Emotional support can reduce the level of depression in the elderly

\section{Data and Methods}

\subsection{Sample}

The data of this paper comes from 2001, 2003, 2006, 2009 and 2012 Population and Development Research Institute of Xi'an Jiao Tong University's study which was conducted in rural areas in Anhui, Chaohu Province, "Well-being of Elderly in Anhui Province, China", Sample size is shown in Table 1:

Table 1. Rural population survey in Anhui Province sample size.

\begin{tabular}{|c|c|c|c|c|c|}
\hline & \multicolumn{5}{|c|}{ Investigation period } \\
\hline & The first period & The second period & The third period & The fourth period & The fifth period \\
\hline Year & 2001 & 2003 & 2006 & 2009 & 2012 \\
\hline Sample & 1800 & 1715 & 1391 & 1067 & 836 \\
\hline Death & 0 & 240 & 236 & 173 & 181 \\
\hline Migrate & 0 & 76 & 57 & 33 & 36 \\
\hline Effective sample size & 1715 & 1391 & 1067 & 836 & 605 \\
\hline
\end{tabular}

The research object is the elderly at the age of 60 years in Chaohu area. The investigation in the area refered to random sample from 12 towns, 6 villages per town. Base years of sample design in 2001 aimed in 1800 elderly people. The proportion of such samples is set at $40 \%$ in order to ensure there is enough number of the elderly who aged 75 years old. The investigation in base years acquired 1715 valid questionnaires totally, the response rate was $95.3 \%$, and four follow-up surveys were conducted with 1391,1067,808 and 605 valid questionnaires respectively. This paper excludes the sample of no children and not to refuse to answer or answer questions, five valid samples were obtained from the survey of $1653,1339,1030,777$ and 578 copies respectively for analysis.

\subsection{Variable Design and Measurement}

\subsubsection{Dependent Variable}

In this study, the dependent variable was the score of the psychological well-being of the 5-wave longitudinal survey over time. Psychological well-being was measured using the CSE-D scale [25]. The scale was used to measure psychological well-being, including nine small questions, three of which were questions about the feelings of the elderly on positive questions over the past week, two for negative questions, two for marginalized problems as well as two questions about the physical symptoms of the elderly, each with 1 = "no", 2 = "sometimes", 3 = "regular" to measure, adjust the direction of positive questions, accumulate the score of 9 questions, ranging from 9 to 27, and the higher the score, the worse the mental welfare of the elderly.

\subsubsection{Independent Variable}

The independent variables are intergenerational support for the 5-wave longitudinal survey over time, including financial support, daily care and emotional support. This paper uses the inter-generational two-way support and exchange, and as a dynamic indicator [10]. Specific measurements are as follows:

(1) Financial support includes getting financial support and providing financial support. The rural elderly get the financial support means "how much does the child have for your money, food or gifts in the past 12 months?" The rural elderly provide financial support means "how much have you paid for the child's money, food or gifts in the past 12 months?" "No" is equal to " 0 " and "yes" is equal to a specific value or 9 value range to represent the number of support. (50 yuan below; 50 99 yuan; 100 199 yuan; 200 499 yuan; 500 999 yuan; 1000 2999 yuan; 3000 4999 yuan; 5000 9999 yuan; 10000 yuan or more). If the surveyed rural elderly can not provide an accurate answer, the investigator may ask the elderly to choose from the range of values and then take the median of the paragraphs (the maximum value of 10000 yuan) to indicate the level of financial support between the elderly and the child. Add the number of inter-generational financial support together and you will get the elderly and children's financial support level, and then take the logarithm of financial supportt level as the corresponding financial support in the model.

(2) Daily care includes receiving assistance with household chores providing assistance with household chores , getting personal care and providing personal care. Inter-generational daily care refers to assistance with household chores (such as 
cleaning, washing, washing, etc.) and the help of living (such as bathing, dressing, etc.) between the children (including their spouses) and their parents during the first 12 months of the survey. In the questionnaire, the daily care is measured by asking the frequency of help between the elderly and their children (including their spouses). The questionnaire converts the four-level frequency of assistance with household chores and personal care into specific values. ( Every day $=4$; at least once a week $=3$; several times a month $=2$; rarely $=1$ ). Accumulate the number of times according to the son, daughter, daughter and son-in-law respectively and you can get the score of each help in daily care. The higher the score, the higher the level of help in intergenerational assistance with household chores or personal care.

(3) The emotional support of this paper consists of three questions: the emotional closeness of the elderly and their children, the situation of the elderly and their children, and the willingness of the child to listen to the concerns and difficulties of the elderly. The answer to the question is a three-level measure that sums the scores of each question in the questionnaire into a total score of the degree of intimacy between the elderly and the child. The score is in the range of 3 to 9 , the scores of all children of the elderly were averaged according to the number of children surveyed, and the score of emotional support level between the elderly and the children was scored. The higher the score, the higher the emotional support level between the elderly and the children. Because the mean of the emotional support level is more representative of the quality of intergenerational relationships than the total, the mean of the emotional support is used as the level of emotional communication between the elderly and the children.

\subsubsection{Control Variable}

The control variables in this study include individual characteristics and family characteristics.

Individual characteristics: (1) Age, sex and marital status are the demographic characteristics. Age is the age of the survey period and is set to dynamic time variables, marital status is divided into married and not married; (2) The status of education, occupation and income are the socio-economic characteristics of the rural elderly, and divided into categories according to the classification of variables: education status (on school or not on school), occupation (whether engaged in agricultural labor), independent economic income (with or without); (3) The health status of the elderly includes the number of chronic diseases and cognitive function. The number of chronic diseases was increased by 12 diseases, and cognitive function was measured by six items.

Family characteristics: (1) The availability of children refers to the labor outflow variables and the total number of children. Labor outflow variable means that the village lives at least one son or daughter (yes or no); (2) The living arrangements of the elderly are divided into four categories: "living alone", "living with their spouses", "living with their children or their spouses and living with only grandchildren". In this paper, the relevant family characteristic variables are set to 5-wave dynamic variables; since other control variables have been basically determined in the base period survey, the other variables are set as base-period static variables.

\subsection{Data Analysis}

In this paper, using the vertical data with nested structure to construct the individual growth model of Hierarchical Linear Models Software. The model can examine the individual development trend of psychological well-being. Five generations of family intergenerational support, the outflow of labor and living arrangements for the elderly and other variables lead to individual differences in psychological well-being of the elderly, at the same time, the psychological well-being of the elderly is also affected by the initial state of psychological well-being and changes between the individuals. The build layer - 1 model is as follows:

$$
Y_{i j}=\beta_{0 j}+\beta_{1 j}(\text { Age }-60)+\beta_{2 j} X_{2 i j}+\beta_{3 j} X_{3 i j}+\ldots+\beta_{p j} X_{p i j}+\gamma_{i j}
$$

$Y_{i j}$ denotes the value of the psychological well-being of the elderly $\mathrm{j}$ at the observation point $\mathrm{i}$, and setting the age to indicate the time variable. Interception $\beta_{0 j}$ is the base-period initial state of the psychological well-being of the elderly, the slope $\beta_{I j}$ is the change rate of psychological well-being of the elderly in the observation period, the slope $\beta_{2 i j} \ldots \beta_{p i j}$ is the rate of change in the impact of changes in mental health of the elderly $\mathrm{j}$ on the five generations of family intergenerational support, the outflow of labor and living arrangements of the elderly. $r_{i j}$ is the residual of layer -1 , indicating that the psychological well-being of the elderly $j$ which has not been interpreted at the observation point $i$.

The layer-2 model constructed in this paper incorporates the base-period control variables to account for individual differences of intercepts in the layer- 1 model $[3,8,10]$. The objective of this study is to examine the significant differences in the impact of family intergenerational support on the rate of change in psychological well-being among different individuals (the elderly), without examining the factors that contribute to the change of intergenerational support. The build layer - 2 model is as follows:

$$
\begin{gathered}
\beta_{0 j}=\gamma_{00}+\gamma_{01}(\operatorname{Sex})+\ldots+\mu_{0 j} \\
\beta_{1 j}=\gamma_{10} \\
\beta_{2 j}=\gamma_{20} \\
\beta_{3 j}=\gamma_{30} \\
\ldots \ldots \\
\beta_{p j}=\gamma_{p 0}
\end{gathered}
$$


The constructed layer-2 model uses individual characteristics and family characteristics at base-period observation to explain the mean level of the base-period psychological well-being and individual differences of the rate of change after base period. $\mu_{0 j}$ is the residual of layer 2 , indicating random measurement error of the second layer.

\section{Results}

During the longitudinal survey, the two-way financial support between the generations shows an increasing trend, while the elderly increased the amount of financial support provided by their children far more than the increase in the amount provided by the elderly to their children, and formed an economic flow mainly from their children to the elderly. The 5-wave survey data show that the elderly personal care with increasing, while the elderly are provided with a decrease in the number of help provided by the elderly. Compared with the base survey, the decrease in the provision of assistance with household chores is greater than the reduction in household chores help, the number of elderly people receiving assistance with household chores and the amount of help with the provision of a decreasing trend; emotional support during the five surveys during the numerical fluctuations are relatively stable. In the longitudinal survey, the psychological well-being status of the elderly was generally declining, suggesting that the elderly were dependent on others to show an upward trend. During the survey, the age trend was consistent with the life expectancy of rural residents in recent years. The proportion of males was in line with the lower proportion of women in life expectancy of older men, and the proportion of elderly people was declining regularly. The majority of the elderly did not attend school, and mainly engaged in household chores or agriculture; the average annual economic income of the elderly is low; the number of chronic diseases in the elderly is close to two, and their cognitive function is at a moderate level; the total number of children is about four; relatively stable, and the proportion of living in non-stem families accounted for about $70 \%$, indicating that the current rural family structure of the new model has emerged. The relevant variable information is shown in Table 2:

Table 2. Descriptive Statistics of All Variables.

\begin{tabular}{|c|c|c|c|c|c|c|}
\hline \multirow[t]{2}{*}{ Variable } & $\begin{array}{l}2001 \\
(N=1653)\end{array}$ & $\begin{array}{l}2003 \\
(N=1339)\end{array}$ & $\begin{array}{l}2006 \\
(N=1030)\end{array}$ & $\begin{array}{l}2009 \\
(N=777)\end{array}$ & $\begin{array}{l}2012 \\
(N=578)\end{array}$ & $\begin{array}{l}\text { Total } \\
(N=5377)\end{array}$ \\
\hline & Mean (SD) & Mean (SD) & Mean (SD) & Mean (SD) & Mean (SD) & Mean (SD) \\
\hline \multicolumn{7}{|l|}{ Dependent variable: } \\
\hline Psychological well-being (CES-D) & $18.62(13.11)$ & $17.47(12.21)$ & $16.11(6.19)$ & $16.50(8.36)$ & $16.30(8.32)$ & $17.30(10.76)$ \\
\hline \multicolumn{7}{|l|}{ Independent variable: } \\
\hline \multicolumn{7}{|l|}{ Intergenerational support } \\
\hline Reveived financial support (Thousands Yuan) & $1.18(1.88)$ & $1.52(1.45)$ & $2.04(1.77)$ & $2.73(2.48)$ & $3.76(4.03)$ & $1.93(2.35)$ \\
\hline Reveived assistance with household chores & $2.58(3.61)$ & $2.25(3.64)$ & $1.99(3.21)$ & $1.93(3.32)$ & $1.69(3.44)$ & $2.19(3.50)$ \\
\hline Provided assistance with household chores & $1.34(2.55)$ & $1.20(2.59)$ & $0.63(1.77)$ & $0.55(1.81)$ & $0.25(1.06)$ & $0.94(2233)$ \\
\hline Reveived personal care & $1.21(2.87)$ & $1.34(3.02)$ & $1.25(2.81)$ & $1.31(2.84)$ & $1.46(3.32)$ & $1.29(2.94)$ \\
\hline Provided personal care & $0.19(0.95)$ & $0.33(1.45)$ & $0.12(0.73)$ & $0.15(0.91)$ & $0.14(0.77)$ & $0.20(1.04)$ \\
\hline Emotional support & $7.05(1.65)$ & $7.22(1.69)$ & $7.19(1.48)$ & $7.22(1.51)$ & $7.20(1.86)$ & $7.16(1.64)$ \\
\hline \multicolumn{7}{|l|}{ The characteristics of the elderly } \\
\hline \multicolumn{7}{|l|}{ Social demographic characteristics } \\
\hline Married status:( $1=$ married $)$ & $0.57(0.50)$ & $0.55(0.50)$ & $0.53(0.50)$ & $0.53(0.50)$ & $0.49(0.50)$ & $0.54(0.50)$ \\
\hline \multicolumn{7}{|l|}{ Socioeconomic status } \\
\hline Education status & $0.21(0.41)$ & $0.21(0.41)$ & $0.27(0.45)$ & $0.27(0.45)$ & $0.21(0.41)$ & $0.21(0.41)$ \\
\hline Career:(1=Agriculture) & $0.93(0.25)$ & $0.94(0.24)$ & $0.94(0.24)$ & $0.95(0.22)$ & $0.97(0.16)$ & $0.94(0.23)$ \\
\hline Income:(Thousands Yuan) & $0.84(1.53)$ & $0.93(1.86)$ & $1.28(2.37)$ & $1.66(4.15)$ & $3.26(1.47)$ & $1.33(5.36)$ \\
\hline \multicolumn{7}{|l|}{ Health status } \\
\hline Number of chronic disease & $1.97(1.51)$ & $1.48(1.26)$ & $1.90(1.48)$ & $1.84(1.54)$ & $2.02(1.62)$ & $1.82(1.48)$ \\
\hline Cognitive function & $7.32(2.92)$ & $7.32(2.92)$ & $6.98(3.02)$ & $7.42(3.04)$ & $7.52(3.36)$ & $7.29(3.01)$ \\
\hline \multicolumn{7}{|l|}{ Family characteristics } \\
\hline Living arrangements:(living alone) & $0.20(0.40)$ & $0.21(0.41)$ & $0.21(0.41)$ & $0.25(0.43)$ & $0.33(0.47)$ & $0.23(0.42)$ \\
\hline Living with their spouses & $0.28(0.45)$ & $0.29(0.45)$ & $0.27(0.45)$ & $0.33(0.47)$ & $0.37(0.48)$ & $0.30(0.46)$ \\
\hline Living with their children or their spouses & $0.34(0.47)$ & $0.30(0.46)$ & $0.34(0.47)$ & $0.26(0.44)$ & $0.25(0.43)$ & $0.31(0.46)$ \\
\hline Living with only grandchildren & $0.17(0.38)$ & $0.19(0.39)$ & $0.18(0.38)$ & $0.15(0.36)$ & $0.06(0.23)$ & $0.16(0.37)$ \\
\hline The total number of children & $4.00(1.60)$ & $4.03(1.60)$ & $4.08(1.58)$ & $4.02(1.57)$ & $4.04(1.53)$ & $4.03(1.58)$ \\
\hline The village lives at least one son:(1=yes) & $0.50(0.50)$ & $0.48(0.50)$ & $0.45(0.50)$ & $0.46(0.50)$ & $0.43(0.50)$ & $0.47(0.50)$ \\
\hline
\end{tabular}

Note: Data Sources: Sampling and follow-up survey of "Well-being of Elderly in Anhui Province, China".

Table 3 presents a gradual analysis of the various variables supported by family intergenerational support and the impact of control variables on the psychological well-being of the elderly. In this study, we constructed an unconditional and individual growth model under various family structures for psychological well-being. The results showed that psychological well-being decreased significantly with age during the five periods, and there were significant differences 
between individuals. Table 3 is a regression model of intergenerational support and related factors affecting the psychological well-being of the elderly. Model 1 to Model 3 reflect the progressive regression results of intergenerational support and its associated factors on psychological well-being. Model 4 to Model 9 examine the situation of different family structures in reality, ie, the regression results of the effects of different family intergenerational support combinations on the psychological well-being effects of six more than 5\% probabilities in the sample. In reality, the six models corresponding to the family structure may be: model 4 for "empty nest" families (including solitary families), model 5 for the network family, model 6 to model 8 is more likely to be the stem family, model 9 for generations family. Among them, Model 6 reflects the elderly family can not take care of their own in the trunk family, model 7 reflects the health of the elderly can still be the stem family, the model 8 is the elderly reflect the three generations of the stem family.

Table 3 shows that providing financial support for their children, providing assistance with household chores for their children (including grandchildren), and intergenerational emotional support significantly and steadily enhance the psychological well-being of the elderly, and the significant influence of financial support has gradually weakened after gradually considering the labor outflow variables and the individual characteristics of the elderly. The financial support provided for children (including grandchildren) can improve the psychological well-being of the elderly, but after gradually considering the labor outflow variables and the individual characteristics of the elderly, the support for its The positive effects of psychological well-being are gradually disappearing; receiving assistance with household chores from their children significantly reduces the psychological well-being of the elderly, but their significant influence is weakened after taking into account the individual characteristics of the elderly; receiving financial support, personal care and providing personal care can not constitute a significant impact on the elderly psychological well-being. The significant adverse effects of age on psychological well-being were weakened after controlling the individual characteristics of the elderly. The initial level of psychological well-being of the elderly increased with the increase of the cognitive function level.

Table 3. Growth Curve Models of Intergenerational Support Effects on Psychological Well-being $(N=5377)$.

\begin{tabular}{|c|c|c|c|c|c|c|c|c|c|}
\hline Fixed Effect & Model 1 & Model 2 & Model 3 & Model 4 & Model 5 & Model 6 & Model 7 & Model 8 & Model 9 \\
\hline Intercept (Level-1) & $30.10 * * *$ & $30.58 * * *$ & $40.87 * * *$ & $39.52 * * *$ & $39.62 * * *$ & $39.70 * * *$ & $40.88 * * *$ & $40.97 * * *$ & $40.63 * * *$ \\
\hline \multicolumn{10}{|l|}{ Slope (Level-1) } \\
\hline Age & $0.18 * * *$ & $0.18 * * *$ & $0.09 * * *$ & $0.11 * * *$ & $0.09 * * *$ & $0.09 * * *$ & $0.07 * *$ & $0.07 * *$ & $0.10 * * *$ \\
\hline Provided financial support (Thousands Yuan) & $-0.95 * * *$ & $-0.98 * * *$ & $-0.82 * *$ & $-0.83 * * *$ & - & - & - & - & $-0.89 * * *$ \\
\hline Reveived assistance with household chores & $0.37 * * *$ & $0.37 * * *$ & $0.29 * * *$ & - & $0.23 * * *$ & $0.21 * * *$ & $0.24 * * *$ & $0.23 * * *$ & - \\
\hline Provided assistance with household chores & $-0.25 * * *$ & $-0.26 * * *$ & $-0.25 * * *$ & - & - & - & $-0.20 * * *$ & $0.23 * * *$ & $-0.20 * *$ \\
\hline Provided personal care & $0.16^{+}$ & $0.16^{+}$ & $0.16^{+}$ & - & - & - & - & 0.12 & 0.15 \\
\hline Emotional support & $-2.94 * * *$ & $-2.95 * * *$ & $-2.75 * * *$ & $-0.81 * * *$ & $-2.78 * * *$ & $-2.78 * * *$ & $-2.77 * * *$ & $-2.77 * * *$ & $-2.74 * * *$ \\
\hline The village lives at least one son: $(1=y e s)$ & & -0.45 & $-0.51^{+}$ & -0.45 & $-0.50^{+}$ & $-0.50^{+}$ & -0.46 & -0.47 & -0.41 \\
\hline The village lives at least onedaughter: (1=yes) & & 0.14 & 0.15 & 0.28 & 0.13 & 0.13 & 0.17 & 0.17 & 0.31 \\
\hline \multicolumn{10}{|l|}{ Living arrangements: (living alone) } \\
\hline living with their spouses & & -0.20 & 0.51 & 0.58 & 0.61 & 0.62 & 0.61 & 0.61 & 0.58 \\
\hline living with their children or their spouses & & 0.00 & -0.09 & 0.21 & -0.23 & -0.22 & 0.02 & 0.02 & 0.44 \\
\hline \multicolumn{10}{|l|}{ Intercept (Level-2) } \\
\hline Gender: (Male=1) & & & -0.12 & -0.08 & -0.01 & -0.01 & -0.09 & -0.10 & -0.16 \\
\hline Married status:(1=married $)$ & & & $-0.68^{+}$ & $-0.95 *$ & $-0.76^{*}$ & $-0.76^{*}$ & $-0.80 *$ & $-0.80 *$ & $-0.99 *$ \\
\hline Status of education & & & $0.87 *$ & $0.90 *$ & $0.86^{*}$ & $0.86^{*}$ & $0.85 *$ & $0.86^{*}$ & $0.90 *$ \\
\hline Career: (1=Agriculture) & & & -0.39 & -0.54 & -0.43 & -0.43 & -0.45 & -0.46 & -0.56 \\
\hline Income (Thousands Yuan) & & & -0.00 & -0.00 & -0.00 & -0.00 & -0.00 & -0.00 & -0.00 \\
\hline The total number of children & & & $-0.17^{+}$ & -0.15 & -0.15 & -0.15 & -0.16 & -0.16 & -0.15 \\
\hline Number of chronic disease & & & 0.08 & 0.14 & 0.11 & 0.11 & 0.09 & 0.09 & 0.13 \\
\hline Cognitive function & & & $-0.93 * * *$ & $-0.96 * * *$ & $-0.94 * * *$ & $-0.94 * * *$ & $-0.93 * * *$ & $-0.93 * * *$ & $-0.95 * * *$ \\
\hline \multicolumn{10}{|l|}{ Random Effect } \\
\hline Intercept & $4.07 * * *$ & $4.08 * * *$ & $3.67 * * *$ & $3.80 * * *$ & $3.71 * * *$ & $3.72 * * *$ & $3.69 * * *$ & $3.69 * * *$ & $3.79 * * *$ \\
\hline Level-1 R & 8.49 & 8.49 & 8.39 & 8.39 & 8.39 & 8.39 & 8.39 & 8.39 & 8.38 \\
\hline Deviance & 39161.38 & 39164.47 & 38929.66 & 38962.27 & 38941.56 & 38946.75 & 38935.73 & 38940.56 & 38959.07 \\
\hline
\end{tabular}

Note: ${ }^{*} \mathrm{p}<.05 ; * * \mathrm{p}<.01 ; * * * \mathrm{p}<.001$

\section{Discussion}

In this paper, using the 12-year longitudinal data to establish the individual growth model of psychological well-being of the elderly. In view of the results in Table 3, this paper determines that the gain effect of the "main effect model" can better explain the mechanism of rural family intergenerational support to the psychological well-being of the elderly.

First of all, for the provision of financial support for their children, receiving assistance with household chores, providing assistance with household chores and 
intergenerational emotional support significantly and steadily improve the psychological well-being of the elderly, the results of this article are as follows:

1) The rural elderly provide the financial support can significantly improve the psychological well-being of their, to meet their ability to work on their own proof, so as to promote its body function and maintain a good psychological experience, and ultimately to psychological well-being is at a high level; at the same time, based on the "role enhancement" theory, this is because the elderly to provide financial support, in the process of providing economic assistance to their children, the elderly have a great sense of satisfaction and sense of accomplishment is good for the elderly psychological well-being development, making the elderly self-worth to be reflected, thereby reducing the degree of depression.

2) The aging led to the rural elderly immune function and physical decline, the provision of assistance with household chores to help children is the old age of life of rural parents to protect the quality of life, but the reality of rural elderly always life until the health problems will accept children of the assistance with household chores. Elderly people receive assistance with household chores to show that their health has been a problem, daily life is subject to certain obstacles. In this case, the elderly will realize that they are useless, has become a child's burden, dampened the exchange of feeling, breeds a sense of inferiority, which is not conducive to the healthy development of psychological well-being, the elderly have a significant impact on the degree of depression.

3 ) The reality of the elderly are always as much as possible for their children to provide assistance with household chores. For the children to provide household help to reflect the elderly parents are well-being; in this process reflects the elderly have a good sense of exchange and harmonious intergenerational relationship; and then, grandparents care for the left-behind grandchildren can lift their children to worry about, so as to enable the elderly to achieve their children's "Guangzongyaozu" expectations and contribute indirectly to the prosperity of the family, so as to meet their psychological needs (Including self-esteem and self-realization), and consolidate the sense of social exchange and life control.

4) Generational emotional communication has significantly improved the development level of elderly psychological well-being. In this regard, this study argues that because of the reality of the rural elderly narrow life circle, the monotonous life and dependence on children's support, it shows that the harmonious intergenerational relationship can be isolated for the elderly loneliness, so that they perceive the potential support and from the threat of future stress events, so that the elderly can be positive attitude and way to treat their physical and psychological well-being. Family members should care about each other, consciously establish and practice the concept of responsibility of respect for the elderly, love the old and respect for the elderly and take the initiative to fulfill the elderly "nurturing" obligations. It is necessary to attach importance to material pension, but also attach importance to spiritual endowment. In short, the emotional support provided by their children can meet their emotional lack of demand, which reflects the "main effect model" of the gain effect.

Secondly, the rural elderly get financial support and get personal care to help significantly reduce the degree of depression. To provide children with personal care is not conducive to the healthy development of psychological well-being and variable significant influence in the control of individual characteristics weakened. In this regard of this study that:

1) Access to financial support provided by children can improve the living conditions of the rural elderly, to meet their lack of pension needs and improve their psychological well-being. At the same time, in the context of Confucian culture, children in their parents in old age to provide financial support so that the elderly in rural areas feel that their son has a good way to pay a return, which ensures that they can experience a positive psychological experience in dealing with others. Therefore, in the rural areas where the formal pension system is lacking, the effect of the "main effect model" is the mechanism of family intergenerational support to psychological well-being.

2) The rural elderly receive personal care can help make up for the decline with self-care ability to meet the needs of the elderly can not take care of their own lack of demand, which can slow down the old parents' illness, and even prolonged life. That the significant influence of this support in considering the characteristics of the elderly after the weakening of the results reflects some of the individual characteristics of intergenerational support for psychological well-being of the intermediary variables. There is a significant impact on thepsychological well-being of the elderly. With the decline of the ability to work and the health of the body, the elderly parents are responsible for the heavy household help, which undoubtedly bring them a heavy psychological burden.

In addition, the significant impact of age on the development of psychological well-being in the control of the elderly after the disappearance of individual characteristics, In this regard, this study is influenced by oriental culture, Chinese elderly people to physical discomfort to express the lack of energy, depression, that is, their psychological feelings are more likely to be caused by physical symptoms of the illusion, rather than aging caused. The level of psychological well-being of the elderly non-living alone is significantly higher than the level of the control group, reflecting the elderly want to spend their old age in the family, hoping to witness the family changes, so family relationships and fear of loneliness is the key to psychological well-being factor. There was a significant positive correlation between the status of education and the initial mean value of psychological well-being of the elderly, and there was a significant positive correlation between the cognitive function and the psychological well-being of the initial state, indicating that the base period was educated and the basis of cognitive function Differences have affected the expression of the elderly, the scope and willingness, which is not conducive to their psychological well-being improvement. Moreover, the older educated older people have better language skills and can express their psychological status more accurately, resulting in 
lower psychological well-being at the base period. However, this article can not rule out the educational status of the elderly in the psychological well-being The impact may be false, because the education situation is likely to make the elderly and the outside world more smoothly, and not the elderly psychological well-being level becomes lower.

\section{Conclusion}

This paper is a study of the impact of Chinese rural family intergenerational support on the development trend of psychological well-being of the elderly under the background of labor outflow. The study found: The financial support of the elderly in rural areas, providing financial support for intergenerational two-way financial movement significantly improve their psychological well-being; The rural elderly get home help to significantly reduce their psychological well-being level; Rural elderly as much as possible for their children to provide assistance with household chores to significantly improve their mental health; The elderly in rural areas get personal care to help their psychological well-being is conducive to the level of improvement; Rural elderly children to personal care help is not conducive to their psychological well-being; Intergenerational emotional support significantly help the rural elderly have a good psychological well-being development.

Based on the above conclusions, combined with the unique socio-economic and cultural background of rural areas in China and the status quo of family pension, in order to improve the health level and quality of life of rural elderly, this study makes the following suggestions: First of all, pay attention to family pension in the rural old-age security system in the important position. Social old-age security can not completely replace the family pension. It can only support the family to play its positive role to provide a better external environment. Secondly, governments at all levels should regard psychological well-being and physical health as important as possible, and actively establish and improve the rural health care system, including psychological well-being protection, and give more policy to the psychological well-being of the rural disadvantaged groups. Again, through the psychological promotion mechanism, to achieve the psychological well-being of the elderly. Psychological promotion mechanism is to help and promote the elderly to adjust and improve the psychological status, psychological well-being to achieve the action and process. This includes two aspects: First, the popularization of psychological well-being education, improve the elderly self-care awareness and self-regulation ability; the second is to create a good external environment, to promote the psychological well-being of the elderly. The above two aspects can be implemented: the village groups at all levels should be under the guidance of the government to diversify the lives of rural elderly for their multi-organization meaningful activities and to participate in the expression of their own value, so that their dependence on their children can maintain a degree. And vigorously promote volunteer service for the rural elderly spiritual and cultural life services to contribute to and develop relevant laws and regulations, so that volunteer service standardization and institutionalization. Department of the environment, to promote the psychological well-being of the elderly. Of course, to establish a national, community, family and elderly individual multi-level staggered security system requires the joint efforts of society as a whole, can better improve the physical and psychological well-beingof the elderly and quality of life.

\section{Acknowledgements}

Fund project: National Natural Science Foundation of China: Dynamic Evolution and Family Support Policy for Rural Livelihoods and Welfare (71573207); National Social Science Fund Project: Impact of Child Migration on Old Age and Health Status of Rural Elderly Family (10BRK010).

\section{References}

[1] Li Quan, Yang Tongwei, Chen Xiaoyang. On the Influence of Family Structure Change on the Rural Traditional Old - age Care Model [J]. Dongyue Tribune, 2014, 35 (5).

[2] Tao Yuchun. The Influence of Social Support on the Physical and Mental Health of the Rural Elderly [J]. Population\&Economic, 2014 (3): 3-14.

[3] Wang Ping, Gao Bei. A Longitudinal Study of the Effect of Intergenerational Support on Cognitive Function of Rural Elderly [J]. Population Journal, 2011, (03): 70- 79.

[4] Li Bingshui, Zhao Yingli, Lin Zilin. The Study of the Effect of Family Family Support on Psychological Health in the Elderly Citizens [J]. Journal of Jiangsu University (Social Science Edition), 2013, 15 (4): 62-68.

[5] Morab A H, Yadav V S, Khadi P B. Mental health of rural elderly [J]. Karnataka Journal of Agricultural Sciences, 2014, 27 (3).

[6] He Bin. Current situations on and the influencing factors for mental health, social support, and coping strategies among left-behind elderly in rural China [J]. Modern Preventive Medicine, 2014, 41 (12): 2184-2187.

[7] Li Min. Mental Health Management of Middle - aged and Old People [M]. Liaoning Normal University Press, 2013.

[8] Wang Ping, Li Shuzhuo. A Longitudinal Study of the Dynamic Effect of Intergenerational Supporton Life Satisfaction of Rural Elderly [J]. Population Research, 2011 (01): 44-52.

[9] Zhang Wenjuan, Li Shuzhuo. Effects of Inter-generation Support on Physical and Psychological Health Status of the Oldest-Old [J]. Chinese Journal of Population Science, 2004 (S1).

[10] Wang Ping, Li Shuzhuo. The Effect of Intergenerational Support on Physical Health of Rural Elderly Under the Background of Out - migration of Young Adults [J]. Population and Development, 2012, 18 (02): 61-71.

[11] $\mathrm{Mu}$ Yingtan, Yuanxin. The Familism Fundamental of Inter-generational Support: What Have Changed by Only-child?-An Empirical Analysis Based on Survey Data [J]. Northwest Population Journal, 2016, 37 (1). 
[12] Mudrazija S. Measuring intergenerational financial support: Analysis of two cross-national surveys [J]. Demographic Research, 2015, 33 (1): 951-984.

[13] Hurley K, Tuffin M B K. Intergenerational inequity arguments and the implications for state-funded financial support of older people [J]. Ageing \& Society, 2015: 1-20.

[14] Song L, Li S, Zhang W, et al. Intergenerational Support and Self-rated Health of the Elderly in Rural China: An Investigation in Chaohu, Anhui Province [M]// Healthy Longevity in China. Springer Netherlands, 2008: 235-249.

[15] Wu S. Hong Kong intergenerational upward financial support [D]. The University of Hong Kong (Pokfulam, Hong Kong), 2014.

[16] Anderson K, Harwood J, Hummert M L. The Grandparent-Grandchild Relationship: Implications for Models of Intergenerational Communication $[\mathrm{J}]$. Human Communication Research, 2005, 31 (31): 268-294.

[17] Zhang Wenjuan. Sons, Daughters and Personal Care for the Chinese Oldest_old People [J]. Population \& Economics, 2006 (06): 9-13.

[18] Jin Mengyun, Chen Changchun, Li Shuxing. A Study on the Relationship between Functional Status and Health Status of Elderly [J]. Journal of Hebei Union University: Medical, 2014 (1): 52-53.
[19] Wang Huan, Lu Zhiqi. Mental Health Status and Age Change of The Elderly in Western Cities [J]. Journal of Shanxi Coal-Mining Administrators College, 2016, 29 (2).

[20] Kwag K H, Martin P, Russell D, et al. The impact of perceived stress, social support, and home-based physical activity on mental health among older adults.[J]. International Journal of Aging \& Human Development, 2011, 72 (2): 137-154.

[21] Song Lu, Li Shuzhuo, Li Liang. The Impact of Care for Grandchildrenon Psychological Well-being of the Rural Elderly [J]. Population and Development, 2008 (3): 10-18.

[22] Tomaka J, Thompson S, Palacios R. The relation of social isolation, loneliness, and social support to disease outcomes among the elderly.[J]. Journal of Aging \& Health, 2006, 18 (3): 359-84.

[23] Dai Y, Zhang C Y, Zhang B Q, et al. Social support and the self-rated health of older people: A comparative study in Tainan Taiwan and Fuzhou Fujian province.[J]. Medicine, 2016, 95 (24).

[24] Zhang W, Du P. The Intergenerational Support and Psychological Well-Being of the Elderly in Mainland of China [M]// Successful Aging. Springer Netherlands, 2015: 165-178.

[25] Radloff, L. S.. The CES-D Scale A Self-Report Depression Scale for Research in the General Population [J]. Applied Psychological Measurement, 1977, 1 (3): 385-401. 